\title{
Knowledge of Rural Women Regarding Nutrition Practices in Bikaner District of Rajasthan, India
}

\author{
Suchitra* and Ravindra Kumar \\ Extension Education, Choudhary Parma Ram Godara Agriculture College Bhadra, \\ Hanumangarh, Rajasthan, India \\ *Corresponding author
}

\section{A B S T R A C T}

\section{Keywords \\ Nutrition, \\ Knowledge \\ Article Info \\ Accepted: \\ 26 January 2018 \\ Available Online: \\ 10 February 2018}

The present study was conducted in six panchayat samitis out of which Bikaner panchayat samiti was selected. Out of thirty one Gram panchayat in Bikaner panchayat samiti four Gram panchayat were selected one village was selected on the basis of random sampling technique. Findings revealed that majority of respondents were in the category of medium level knowledge level regarding nutrition practices.

\section{Introduction}

We normally think of our nutrition as personal, affecting only our own lives. This isn't always the case though. The woman who is pregnant, or who may be, must understand that her nutrition today will be critical to the health of her child throughout life. The nutrition demands of pregnancy are extraordinary because the growth of a whole new person requires all the minerals and other nutrients, and most in larger amounts.

During pregnancy, a woman must establish nutritional habits that will optimally nourish both the growing fetus, and herself. She must be well nourished at the outset because in early pregnancy the embryo undergoes rapid and significant developmental changes that depend on her prior balance of minerals, vitamins, and other dietary concerns.

Malnutrition in all its form remains a major public health problem throughout the developing world and is an underlying factor in over 50 per cent of the 10-11 million deaths in children under five years of age. India ranks second in the world for child malnutrition (43.1\%) after Timor lest (43.7\%), according to World Health Statistics Report (WHO, 2012). High malnutrition rates in the country pose a significant obstacle in achieving better child health outcomes (Ragini, 2014). India still has the highest number of under-weight children under five in the world and 70 per cent of children are anemic. The proportion of 
undernourished people in the overall population has fallen from 21.5 per cent in 2004-06 to 17 per cent in 2011-13 according to International Food Policy Research Institute (IFPRI) estimates (Rukmini, 2014). The link between malnutrition and infant feeding has been well established. Poor feeding practices in infant and early childhood resulting in malnutrition contribute to impaired cognitive and social development, poor school performance and reduced productivity in later life. Poor feeding practices are, therefore, a major threat to social and economic development as they are among the most serious obstacles in attaining and maintaining the health of this important age group. A mother is the principle provider of the primary care that her child needs during the first five years of life. Nutritional awareness of mothers plays an important role in the health of children aged 0-5 years. The type of care she provides depends to a large extent on her knowledge and understanding of some aspects of basic nutrition and health care. Mothers educational level, position, health and nutritional status is central to the quality of life and is a key ingredient of her child's health, nutritional status, behavioral and other aspects of child welfare in developing countries. Nationwide as well as micro studies clearly show that incidence of under nutrition among children fell monotonically with the maternal education. This is of particular concern for India due to a low literacy level of 56 per cent for females (census 2011).

\section{Materials and Methods}

The present study was conducted in Bikaner District. There are six panchayat samiti out of which Bikaner panchayat samiti was selected purposely looking to no such study has been conducted in the area earlier and the area was well known to the researcher. Out of thirty one Gram panchayat in Bikaner panchayat samiti four Gram panchayat were selected with lottery method namely KilchooDeodan, Ridmalsarpurohitan, Palana, Nalbari. One village from each selected Gram panchayat selected on the basis of random sampling technique. Thus, four villages were selected for the present investigation. A sample of one twenty rural women in the age groups 15-45 years (30 rural women from each village).

\section{Results and Discussion}

\section{Knowledge level of the respondents in different aspects of nutrition practices}

Table 1 presents information about knowledge of respondents on each aspect of nutrition and their mean per cent score. Perusal of data reveals that out of three aspects, the knowledge for aspect of 'Basics of food and nutrition' ranked first with overall mean per cent score of 58.25. This aspect was in the category of medium knowledge.

The knowledge for the aspect 'Nutrition for mothers' ranked second with overall mean per cent score of 57.13.This aspect was in the category of medium knowledge.

The knowledge for the aspect 'Nutrition for children' ranked third with overall mean per cent score 55.13.This aspect was in the category of medium and low knowledge. Kaur et al., (2015) revealed that knowledge level of mothers was found to be maximum in the area of hygiene and sanitation (93.8\%) followed by feeding practices $(73.7 \%)$ and pregnancy (60.1\%). The knowledge level regarding anemia was very low $(9.8 \%)$. The nutrition knowledge scores of rural mothers were significantly related to age, education, occupation, caste and family income. Maternal nutrition knowledge exerted a significant intervening affect in improving the nutritional status of their children. Awareness of mothers about the nutrition needs to be further improved with special reference to anemia 
with basic nutrition and health education, awareness and proper counseling.

\section{Basics of food and nutrition}

The first aspect of knowledge check was of "Basics of Food and Nutrition" which included 32 items. Table 1 reveals that majority of the respondents $(61.67 \%)$ were in the category of medium knowledge with mean score of $(55.49 \%)$. These respondents could give answers of 13 to 23 items correctly. About 20 per cent respondents were in the category of low knowledge with mean score of $(38.02 \%)$ that is they could correctly answered 10 to 13 items. Remaining (18.33\%) respondents had high knowledge with mean score of $(81.25 \%)$ and answered 23 to 30 items correctly out of 32 items (Fig, 1).

In depth study of the knowledge of "Basics of food and nutrition" bring out that items 'green leafy vegetables contains nutrients as vitamins and minerals' and 'nutrient required for body building and maintenance is protein' were not answered correctly by $(95.83 \%$ and $86.67 \%$ ) respectively). Nutrition knowledge was limited to familiar practices in the actual diet. Attitudes toward complications of pregnancy and illness tended to be fatalistic. Awareness of the importance of maternal nutrition and the harmful effects of insanitary living conditions was evident. Beliefs regarding protein- calorie malnutrition in infants were based on superstition. Although attitude towards weaning was non- traumatic and permissive, prolonged breast feeding without supplementary foods needs to be changed. The overall knowledge, attitude and practices regarding utilization of underutilized green leafy vegetables in selected rural women that is 43.12 percent, 46.12 percent and 49 percent respectively. Rao (2010), Masukuand Lan (2014) and Singh et al., (2015). Cent per cent respondents had knowledge about 'vegetables should be cut immediately before cooking' and 'vegetables should be washed before cooking'.

95.83 per cent of the respondents also disagreed with items as 'green leafy vegetables harm the human body' which shows that rural women are somewhat aware about importance of vegetables. Payghan et al., (2014) found that nutritional knowledge and practices of urban mothers are high compared to rural mothers, while rural and urban mothers had almost equal positive attitude towards nutrition. It has been shown that $68 \%$ of urban respondents and $73 \%$ of rural respondents are avoiding some foods like papaya, coconut, and meat during pregnancy. The above findings can be used to plan a customized nutritional intervention programme aiming to improve the maternal nutritional knowledge and practices and eventually improve the health status of the pregnant mothers especially in rural areas.

\section{Nutrition for mothers}

The second aspect of "Nutrition for Mothers" had 18 items. Table 1 reveals that majority of the respondents $(66.67 \%)$ were in the category of medium knowledge with mean score of 57.08 per cent. These respondents could give answer of 8 to 13 items. About 18.33 per cent had low knowledge with mean score of 32.83 per cent i.e. they could give correctly answers of 4 to 8 items. While only 15 per cent were in the category of high knowledge with mean score of 81.48 per cent, they could give answer of 13 to 16 items (Fig. 2).

In depth study of the knowledge of "Nutrition for mother" bring out that item, "food is not required for fetus' and 'pregnant women's food should be in double quantity than normal women's food' were not answered correctly by ( $90 \%$ and $82.5 \%$ respectively). Rani et al., (2015) revealed their ethnic traditional knowledge treasure which they possessed. In 
spite of their traditional knowledge 50 percent and 57.14 percent of women were not aware of the scientific role and importance of iron and folic acid during pregnancy and about regular vaccines respectively. Around 66.67 percent of women feed the babies as long as it needs and 35.71 percent were not aware of the impact of not breast feeding the baby. Their daily nutritional requirements do not seem to meet their RDA due to lack of awareness or due to unavailability of affordable foods to meet their nutritional needs especially fruits and milk. Nivedita and Shanthini (2016) concluded that knowledge about food rich in iron was poor among the participants. $(74.36 \%)$ claimed to have taken iron supplementation regularly whereas $(9.8 \%)$ had not taken iron supplementation. On hemoglobin estimation it was found that $(62.97 \%)$ of the participants were anemic taking 11 grams as the cut off for anemia. The only significant determinants of hemoglobin levels were regular intake of iron supplements (p value 0.006) and timing of iron consumption ( $\mathrm{p}$ value 0.0262 ).

Cent per cent respondents had knowledge about the items as 'all food items should be included in diet of pregnant women' and 'pregnant women should eat anyone fruit daily' and 'pregnant women should consume more water as compare to other women' 97.5 per cent of the respondents also disagreed with the items as 'breast feeding should not be given to the newly born baby'. This shows that rural women were aware of importance of breast feeding.

\section{Nutrition for children}

The third aspect of knowledge check was 'Nutrition for children' included 22 items. The Table 1 reveals that majority of the respondents $(69.17 \%)$ were in the category of medium knowledge with mean score of 53.1 per cent. These respondents could give answer of 9 to 16 items correctly. About 18.33 per cent of the respondents were in the category of high knowledge with mean score of 79.55 per cent they could give correctly answers of 16 to 20 items. While $(12.5 \%)$ respondents were in low knowledge category with mean score of 32.73 per cent and could give correct answers 7 to 9 items (Fig. 3).

In depth study of the knowledge of 'Nutrition for children' bring out that items 'source of vitamin A are green leafy vegetables', 'critical stage of protein, energy malnutrition is marasmus and kwashiorkor' and 'common deficiency diseases in children are protein energy deficiency, vitamin A deficiency and anemia were not answered correctly by 88.33 per cent, 95.83 per cent and 87.5 per cent respondents respectively. This shows that rural women were not aware of deficiency diseases of children. Majority of the respondents were 'aware of importance of mother's milk and breast feeding' as they answered the items related to mother's milk correctly. Saaka (2014) study assessed the relationship between maternal nutritional knowledge in childcare practices and growth of children living in impoverished rural communities. This was an analytical cross-sectional study which covered a random sample of 991 children aged 0-36 month(s). Multivariate analysis showed that, after adjusting for potential confounders, there was a significant positive association between the childcare knowledge index and mean HAZ $(\beta=0.10, p=0.005)$ but was not associated with mean WHZ. The strength of association increased among women of high socioeconomic status $(\beta=0.15, p=0.014)$ but there was no significant association among women of low socioeconomic status. Increase in maternal childcare knowledge may contribute significantly to child's nutritional status in Ghana if there is concurrent improvement in socioeconomic circumstances of women living in deprived rural communities. 
Relationship between personal and socioeconomic characteristic of the respondents and their knowledge level of nutritional practices

The result indicated in the Table 2 revels that the variables namely, family income, education, mass media exposure and extension contacts had positive and significant relationship and age, training participation had negative significant relationship with the knowledge level of the rural women about nutritional practices.

A critical examination of the data presented in Table 2 reveals that the variables namely "family income, education, mass media contact, extension contact were positively and significantly correlated with relationship with the knowledge level at 1 per cent level of probability and age, training participation had negative significant relationship with the knowledge level of the rural women about health and nutritional practices.

Whereas, the correlation of family type, family size, caste, occupation, social participation, land holding and urban contacts with their knowledge of rural women was non-significant. Sharma (2010) concluded that knowledge of rural respondents had significant association with mass media exposure and training attended.

Whereas no such association was observed in the case of age caste, family type, family type, size of family, income and education. Pandit (2012) concluded that age, education level, mass media had significant association in the aspect of health and sanitation, whereas annual income, extension contact, training attended had non-significant association in the aspect of health and sanitation. Kever et al., (2015) reveal that respondent have high (65.3\%) knowledge of dietary practices and $63.27 \%$ of the respondents have positive attitude towards the practices. Among the factors that impede good dietary practice in the population were cultural belief and poor socio-economic background while regular attendance of ante-natal clinic and good socio economic background enhance good dietary practice among the population.

Test of hypotheses showed no association between age and knowledge, attitude and religious affiliation; however occupation and the attitude of the respondent were statistically significant.

Age and knowledge: The result from Table 2 shows that there was a negative and significant relationship between age and knowledge level of rural women. Which means older women could not acquire knowledge regarding nutrition practices.

Family type and knowledge: The data in Table 2 shows the family type was non- significant relationship with knowledge level of the rural women. It means that the family type did not exert significant influence on the knowledge of rural women about nutrition practices. This might be due to the fact that family type didn't play a significant role in formulating knowledge of rural women about nutrition practices.

Family size and knowledge: It was found that the relationship between the family size and knowledge level of the respondents was nonsignificant.

The trend might be due to that irrespective of their size of family, rural women had knowledge about health and nutritional practices.

These may be certain other factors which contribute for increase in knowledge level like education, better socio-economic condition etc. 
Fig.1 Knowledge level of respondents in practices of basics of foods and nutrition

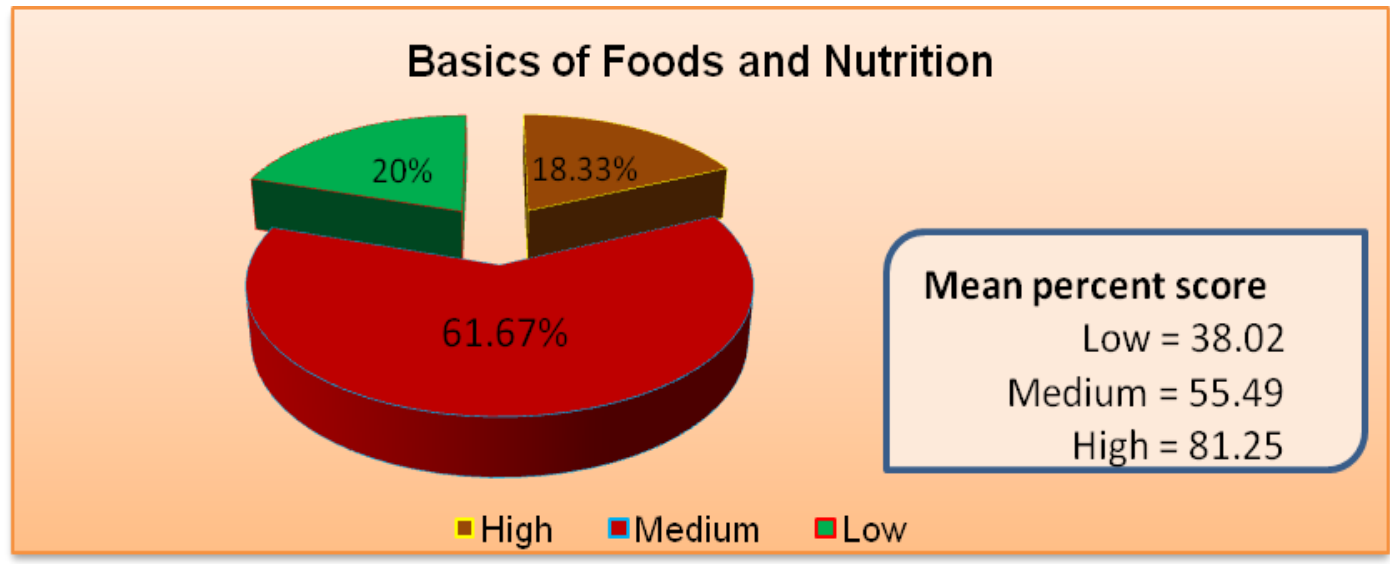

Fig.2 Knowledge level of respondents in nutrition practices for mothers

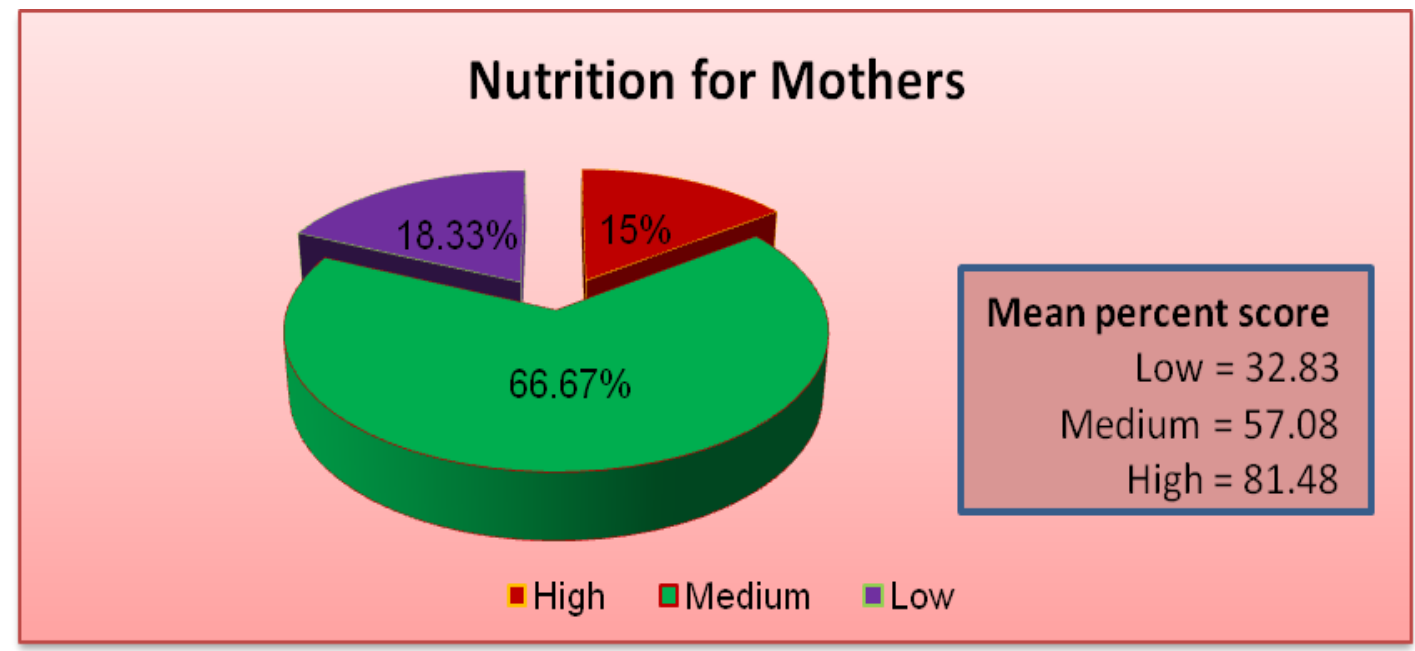

Fig.3 Knowledge level of respondents in nutrition practices for children

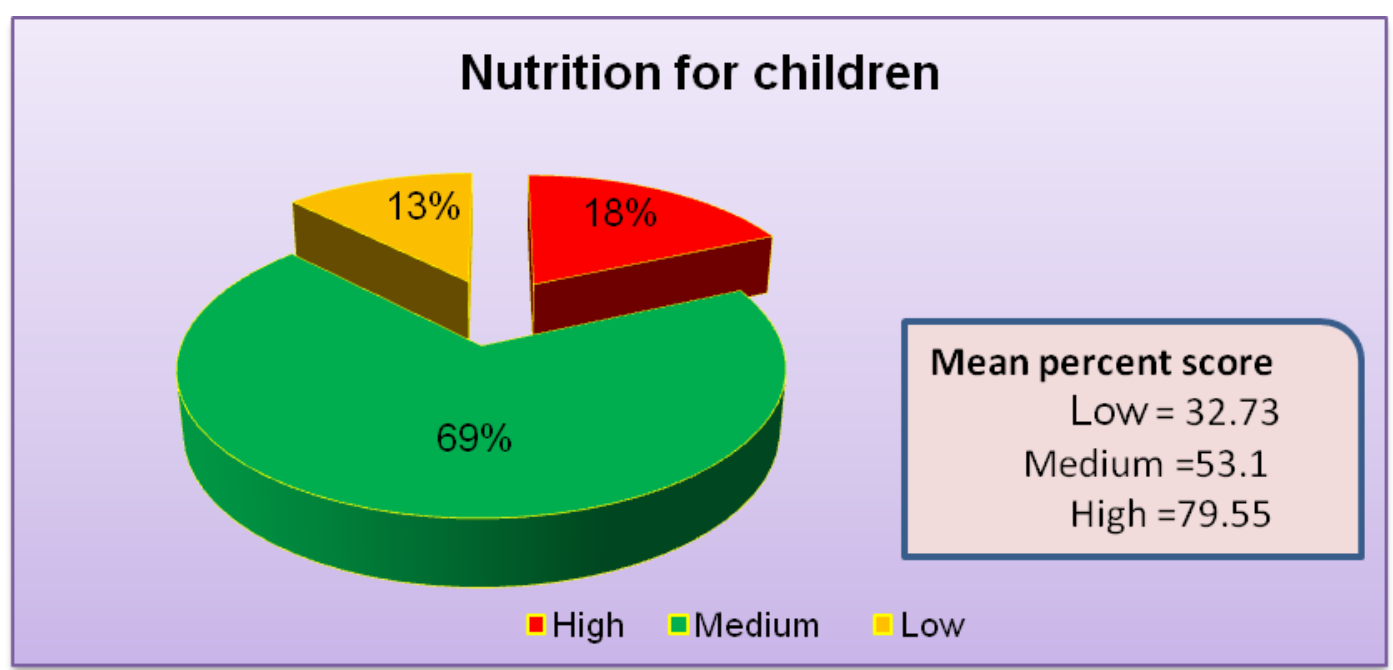


Table.1 Knowledge level of the respondents in different aspects of nutrition practices

\begin{tabular}{|c|c|c|c|c|c|c|c|c|c|}
\hline \multirow{3}{*}{ SN } & \multirow{3}{*}{$\begin{array}{l}\text { Different } \\
\text { aspects }\end{array}$} & \multirow{2}{*}{\multicolumn{3}{|c|}{ Distribution of responses }} & \multirow{2}{*}{\multicolumn{3}{|c|}{ Per cent mean score }} & \multicolumn{2}{|c|}{$\mathrm{N}=120$} \\
\hline & & & & & & & & Overall & Rank \\
\hline & & $\begin{array}{l}\text { High } \\
\text { n }(\%)\end{array}$ & $\begin{array}{c}\text { Medium } \\
\text { n }(\%)\end{array}$ & $\begin{array}{c}\text { Low } \\
\text { n }(\%)\end{array}$ & High & Medium & Low & $\begin{array}{l}\text { mean per } \\
\text { cent score }\end{array}$ & \\
\hline 1. & $\begin{array}{l}\text { Basics of Food } \\
\text { and Nutrition }\end{array}$ & $\begin{array}{c}22 \\
(18.33)\end{array}$ & $\begin{array}{c}74 \\
(61.67)\end{array}$ & $\begin{array}{c}24 \\
(20.0)\end{array}$ & 81.25 & 55.49 & 38.02 & 58.25 & I \\
\hline 2. & $\begin{array}{l}\text { Nutrition for } \\
\text { Mothers }\end{array}$ & $\begin{array}{c}18 \\
(15.0)\end{array}$ & $\begin{array}{c}80 \\
(66.67)\end{array}$ & $\begin{array}{c}22 \\
(18.33)\end{array}$ & 81.48 & 57.08 & 32.83 & 57.13 & II \\
\hline 3. & $\begin{array}{l}\text { Nutrition for } \\
\text { children }\end{array}$ & $\begin{array}{c}22 \\
(18.33)\end{array}$ & $\begin{array}{c}83 \\
(69.17)\end{array}$ & $\begin{array}{c}15 \\
(12.5)\end{array}$ & 79.55 & 53.10 & 32.73 & 55.13 & III \\
\hline
\end{tabular}

Table.2 Relationship between personal and socio-economic characteristic of rural women with their knowledge level

\begin{tabular}{|c|l|c|}
\hline S. No. & Independent variables & Calculated ' $\boldsymbol{r}$ ' value \\
\hline $\mathbf{1 .}$ & Age & $-0.352^{* *}$ \\
\hline $\mathbf{2 .}$ & Family type & $0.106 \mathrm{NS}$ \\
\hline $\mathbf{3 .}$ & Family size & $0.119 \mathrm{NS}$ \\
\hline $\mathbf{4 .}$ & Family income & $0.427^{* *}$ \\
\hline $\mathbf{5 .}$ & Caste & $0.137 \mathrm{NS}$ \\
\hline $\mathbf{6 .}$ & Occupation & $-0.014 \mathrm{NS}$ \\
\hline $\mathbf{7 .}$ & Education & $0.827^{* *}$ \\
\hline $\mathbf{8 .}$ & Mass media contacts & $0.616^{* *}$ \\
\hline $\mathbf{9 .}$ & Social participation & $0.099 \mathrm{NS}$ \\
\hline $\mathbf{1 0 .}$ & Land holding & $0.141 \mathrm{NS}$ \\
\hline $\mathbf{1 1}$ & Urban contacts & $0.138 \mathrm{NS}$ \\
\hline $\mathbf{1 2}$. & Extension contacts & $0.410^{* *}$ \\
\hline $\mathbf{1 3}$ & Training participation & $-0.553^{* *}$ \\
\hline
\end{tabular}

* Significant at $5 \%$ level of probability

** Significant at $1 \%$ level of probability

NS Non Significant

Appendix.1 (A) Respondent's response on selected items regarding nutrition practices

\section{1. (A) Basics of food and nutrition}

\begin{tabular}{|l|l|l|l|l|l|}
\hline & & \multicolumn{4}{|c|}{ Answered } \\
\hline SN. & Questions & \multicolumn{3}{|c|}{ Correct } & Incorrect \\
\hline 1. & Vegetable like carrot, cucumber etc. are not used in raw form & n & \% & n \\
\hline 2. & It is not important to cover the vegetables with a wet cloth in the basket & 115 & 95.83 & 5 & 4.16 \\
\hline 3. & Always cook the pulses in soaked water & 118 & 95.83 & 5 & 4.16 \\
\hline 4. & Nutrient required for body building and maintenance is protein & 16 & 13.33 & 104 & 86.67 \\
\hline 5. & Green leafy vegetables contains vitamins and minerals & 5 & 4.16 & 115 & 95.83 \\
\hline 6. & Energy providing food is rice & 11 & 9.16 & 109 & 90.83 \\
\hline 7. & Rice should be washed with cold water & 119 & 99.16 & 1 & 0.83 \\
\hline 8. & Vegetable should be washed before cooking & 120 & 100 & - & - \\
\hline 9. & Vegetable should be cut immediately before cooking & 120 & 100 & - & - \\
\hline
\end{tabular}


Appendix.1 (B)

\section{1. (B) Nutrition for mother}

\begin{tabular}{|c|c|c|c|c|c|}
\hline \multirow[b]{3}{*}{ SN. } & \multirow[b]{3}{*}{ Questions } & \multicolumn{4}{|c|}{ Answered } \\
\hline & & \multicolumn{2}{|c|}{ Correct } & \multicolumn{2}{|c|}{ Incorrect } \\
\hline & & $\mathbf{n}$ & $\%$ & $\mathbf{n}$ & $\%$ \\
\hline 1. & All food items should be included diet of pregnant women & 120 & 100 & - & - \\
\hline 2. & Food is not required for the fetus & 12 & 10 & 108 & 90 \\
\hline 3. & Pregnant women should eat anyone fruit daily & 120 & 100 & - & - \\
\hline 4. & Breast feeding should not be given the newly born baby & 117 & 97.5 & 3 & 2.5 \\
\hline 5. & $\begin{array}{l}\text { Pregnant women should consume more water as compare to } \\
\text { other women }\end{array}$ & 120 & 100 & - & - \\
\hline 6. & $\begin{array}{l}\text { Pregnant women food should be in double quantity than } \\
\text { normal women }\end{array}$ & 21 & 17.5 & 99 & 82.5 \\
\hline
\end{tabular}

\section{1. (C) Nutrition for children}

Appendix.1 (c)

\begin{tabular}{|c|c|c|c|c|c|}
\hline \multirow[b]{3}{*}{ SN. } & \multirow[b]{3}{*}{ Questions } & \multicolumn{4}{|c|}{ Answered } \\
\hline & & \multicolumn{2}{|c|}{ Correct } & \multicolumn{2}{|c|}{ Incorrect } \\
\hline & & $\mathbf{n}$ & $\%$ & $\mathbf{n}$ & $\%$ \\
\hline 1. & $\begin{array}{l}\text { Mother milk is nutrient rich, easily available, pure, } \\
\text { protective and appropriate temperature }\end{array}$ & 113 & 94.16 & 7 & 5.83 \\
\hline 2. & Breast feeding should be done as much as possible & 120 & 100 & - & - \\
\hline 3. & Source of vitamin A is green leafy vegetables & 14 & 11.67 & 106 & 88.33 \\
\hline 4. & $\begin{array}{l}\text { Common deficiency disease in children are protein energy } \\
\text { deficiency, vitamins A deficiency and anemia }\end{array}$ & 15 & 12.5 & 105 & 87.5 \\
\hline 5. & Protein, energy malnutrition occurs due to lack of & 14 & 11.67 & 106 & 88.33 \\
\hline 6. & $\begin{array}{l}\text { Critical stage of protein, energy malnutrition is marasmus } \\
\text { and kwashiorkor }\end{array}$ & 5 & 4.17 & 115 & 95.83 \\
\hline
\end{tabular}

Family income (monthly) and knowledge: The relationship between family income and knowledge level was significant at 1 per cent level of probability. The possible reason could be that the monthly income plays an important role in getting the formal education, purchasing the nutritional diet and also made the respondents to know the new things regarding nutritional practices. Therefore, the women from higher income group usually possess radio and television and newspapers which in turn results to greater exposure to the new things and they are accessible to the education. These facts might have motivated the higher income group women to seek more information about nutritional practices results in the significant relation with the knowledge.
Caste and knowledge: The data presented in Table 2 shows that caste was non-significant relationship with the knowledge of rural women about health and nutrition practices. It means that the caste did not exert significant influence on knowledge of rural women about nutrition practices. This might be due to the fact that cast didn't play a significant role in formulation of knowledge of rural women about nutrition practices.

Occupation and knowledge: The results from the Table 2 show that negative and nonsignificant relationship between occupation and knowledge level of the rural women. The possible reason from finding a non-significant relationship between the occupation and 
knowledge level, as occupation was not an important factor in stimulating rural women to further action. This means the irrespective of their occupation rural women had knowledge about nutrition practices, the other factors that might have contributed for increase in knowledge level could be education, better socio-economic condition etc.

Education and knowledge: Education was positively and significantly related to the knowledge level of the rural women. The possible reason is a known fact that formal education widens the horizons of knowledge of an individual. Formal education of the respondents might have helped them to a greater extent in understanding the importance of health and nutrition to know more and more about the nutrition practices.

Mass media contact and knowledge: The relationship between mass media contact and knowledge level was significantly at 1 per cent level of knowledge. The respondents who had high level of mass media exposure had more knowledge about different aspect of nutrition practices.

Social participation and knowledge: The relationship between social participation and knowledge level was non-significant. It means that the social participation did not exert significant influence on the knowledge of rural women about nutrition practices. This might be due to the fact that social participation didn't play a significant role in knowledge of rural women about nutrition practices.

Land holding and knowledge: The data presented in Table 2 indications that the relationship between land holding and knowledge level was non-significant. It means that the land holding did not exert significant influence on the knowledge of rural women about nutrition practices. This might be due to the fact that land didn't play a significant role in formulation knowledge of rural women about nutrition practices.

Urban contacts and knowledge: The data presented in Table 2 suggested that urban contact was non-significantly relationship with knowledge of rural women about nutrition practices. The non- significant correlation might be due to the reason that urban contact did not play any significant role in knowledge about nutrition practices.

Extension contacts and knowledge: The relationship between contact and knowledge level was significant at 1 per cent level of probability. It is natural that the extension contacts like Krishi Vygan Kendar, political leader, subject matter specialist, village supervisors, local leader and friends had direct effect on the knowledge level of the respondents.

Training participation and knowledge: The data presented in Table 2 shows that training participation was negatively and significant with the knowledge of the rural women about nutrition practices.

The findings regarding knowledge of respondents on nutrition practices shows that majority of the respondents did not answer the more technical items correctly than other general items included in the knowledge test as 'green leafy vegetable contains nutrition as vitamins and minerals', 'food is not required for fetus', 'sources of vitamin A are green leafy vegetables' and 'critical stages of protein, energy malnutrition is marasmus and kwashiorkor' etc.

This might be due to the reason that the rural women were not aware of these terms; may be due to low education level of respondents, low mass media exposure, low training 
participation and urban contacts and extension contacts.

The variables namely "family income, education, mass media contact, extension contact were positively and significantly correlated with the knowledge level and training need of the rural women about health and nutritional practices at 1 per cent level of probability age and training participation had negative significant relationship with the knowledge level and training needs of the rural women about health and nutritional practices. Whereas, the correlation of family type, family size, caste, occupation, social participation, land holding and urban contacts with knowledge and training needs of rural women regarding health and nutrition practices was non-significant.

\section{References}

Census. 2011. Punjab Population Census2011.co.in

Kaur, K. Grover, K. and Kaur, N. 2015. Assessment of Nutrition Knowledge of Rural Mothers and Its Effectiveness in Improving Nutritional Status of Their Children. Indian Research Journal Extension Education. 15 (4): 90-98.

Kever, R.T. RN, M.Sc., Martins, S.D. RN, RM, M. Sc., FWACN., Lola, N. RN, RM, BNSc., Dathini, H RN, RM, BNSc, PGDE, Habu, H. RN, BNSc., Fatima, A.A. RN, RM, BNSc, PGDE, Sambo B D. RN BNSc. 2015. Knowledge and attitude of pregnant Women towards dietary practices in Yerwa Clinic, Maiduguri Metropolitan Council; Borno State. Journal of Research in Nursing and Midwifery. 4(1): 12-19.

Masuku SK, Lan SJ. 2014. Nutritional knowledge, attitude, and practices among pregnant and lactating women living with HIV in the Manzini region of Swaziland. Journal Health Population Nutrition. 32(2):261-9.

Nivedita K., and Shanthini N. 2016.Knowledge, attitude and practices of pregnant women regarding anemia, iron rich diet and iron supplement. International Journal of Reproduction Contraception, Obstetrics and Gynecology. 5(2) http://www.ijrcog.org Pandit, A. (2012).Video Programme on Health and Sanitation for Rural Women. M.Sc. thesis, Department of Extension Education and Communication Management, Swami Keshwan and Rajasthan Agricultural University, Bikaner.

Payghan, BS., Kadam*, S. S and Reddy, R. M. 2014. A comparative study of Nutritional Awareness among UrbanRural Pregnant Mothers. Journal of Medical and Health Sciences. http://www.rroij.com

Ragini. 2014. Prevalence and risk factors of malnutrition in 1-5 year old children in an urban slum of Ludhiana, Punjab. 46th Annual National Conference of Nutrition Society of India, P116.

Rani P.R. Devi. T, Sowndariya R. and Pratheeba B. 2015. Knowledge, Attitude and Practices on Pregnancy and Post-partum Care among Rural and Tribal Women. Indian Journal of Research in Food Science and Nutrition. 2(1):10-16.

Rao, M. 2010. Knowledge, attitude and practice regarding nutrition among pregnant women in rural Dharwad, Karnataka, India. Journal of Ecology of Food and Nutrition. 18(1986): 3.

Rukmini S. 2014. Malnourishment declined sharply among children in India: Survey. The Hindu.

Saaka. M. 2014. Relationship between Mothers' Nutritional Knowledge in Childcare Practices and the Growth of Children Living in Impoverished Rural 
Communities. Journal of Health, Population, and Nutrition. 32(2): 237248.

Sharma, B. (2010). Health and Nutrition Knowledge of Adolescent Girls of Bikaner District. M.Sc. thesis, Department of Extension Education and Communication Management, Swami Keshwanand Rajasthan Agricultural University, Bikaner.

Singh J. Neeru Balaand Verma A. 2015.
Knowledge attitude and practices of rural women regarding underutilized green leafy vegetables in Allahabad district. International Journal of Applied And Pure Science and Agriculture. 01(9): 25-30.

WHO. 2012. World Health Statistics Report (http://apps.who.int/iris/bitstream/1066 5/44844/1/9789241564441_eng.pdf).

\section{How to cite this article:}

Suchitra and Ravindra Kumar. 2018. Knowledge of Rural Women Regarding Nutrition Practices in Bikaner District of Rajasthan, India. Int.J.Curr.Microbiol.App.Sci. 7(02): 31743184. doi: https://doi.org/10.20546/ijcmas.2018.702.382 